Marquette University

e-Publications@Marquette

Civil and Environmental Engineering Faculty

Civil and Environmental Engineering, Department

Research and Publications

$3-1-2001$

An Evaluation of Age Effects on Driver Comprehension of Flashing Traffic Signal Indications using Multivariate Multiple Response Analysis of Variance Models

Alexander Drakopoulos

Marquette University, alexander.drakopoulos@marquette.edu

Richard W. Lyles

Michigan State University

Accepted version. Journal of Safety Research, Vol. 32, No. 1 (March 2001): 85-106. DOI. (C) 2001

Elsevier B.V. Used with permission. 
Marquette University

\section{e-Publications@Marquette}

\section{Civil, Construction, and Environmental Engineering Faculty Research and Publications/College of Engineering}

This paper is NOT THE PUBLISHED VERSION; but the author's final, peer-reviewed manuscript. The published version may be accessed by following the link in the citation below.

Journal of Safety Research, Vol. 32, No. 1 (March, 2001). DOI. This article is @ Elsevier and permission has been granted for this version to appear in e-Publications@Marquette. Elsevier does not grant permission for this article to be further copied/distributed or hosted elsewhere without the express permission from Elsevier.

\section{Contents}

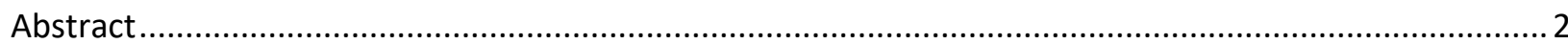

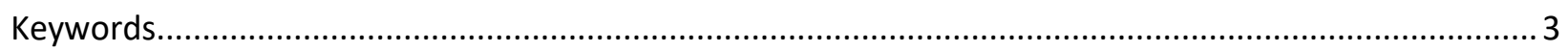

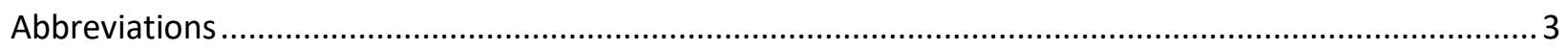

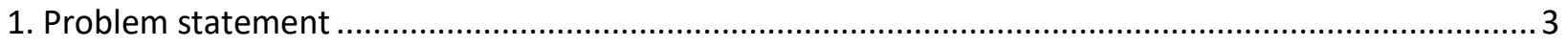

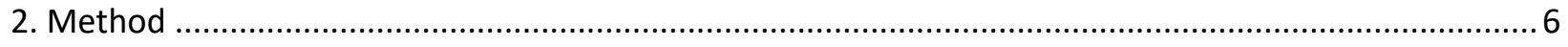

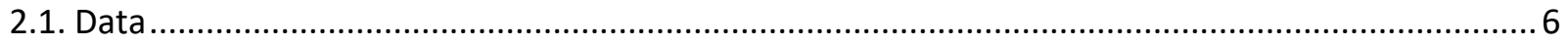

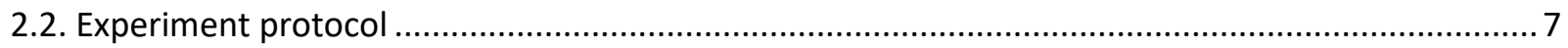

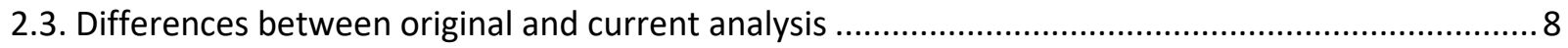

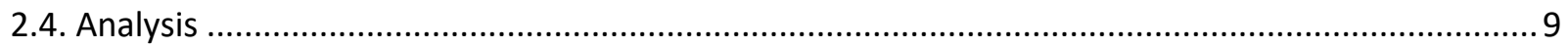

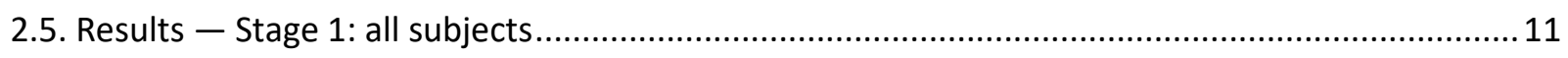

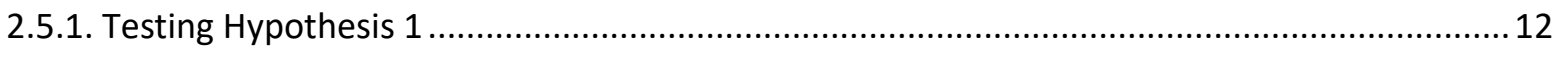

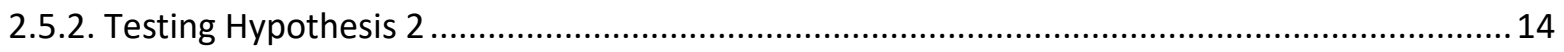

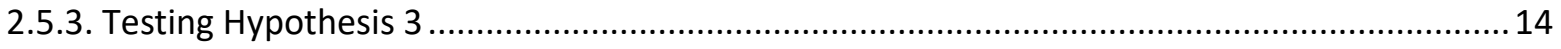

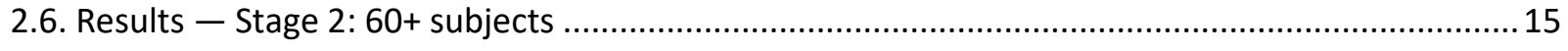

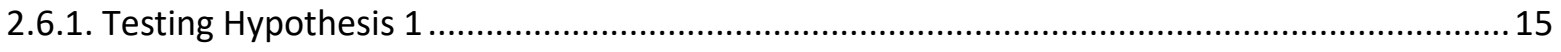

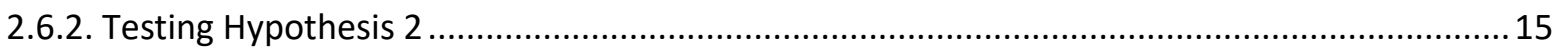

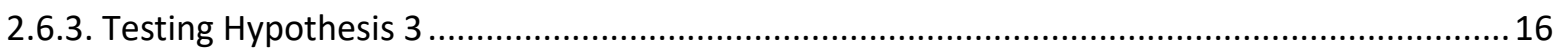




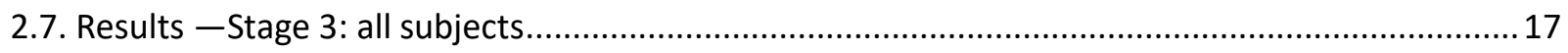

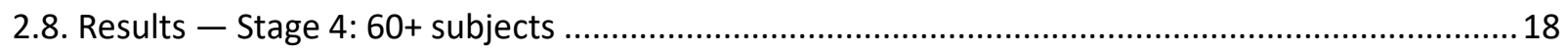

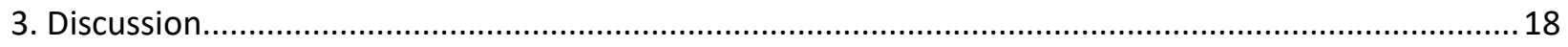

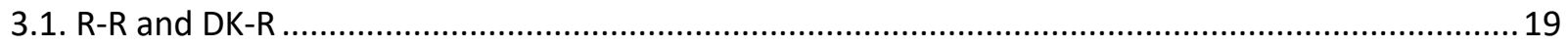

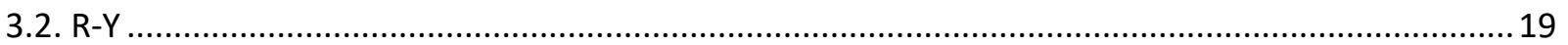

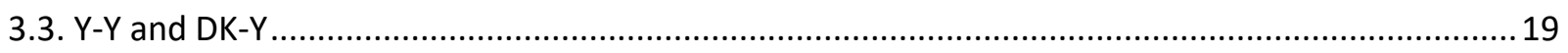

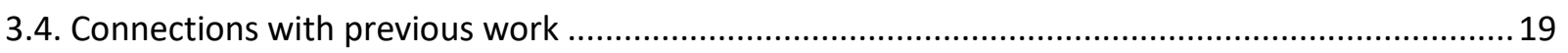

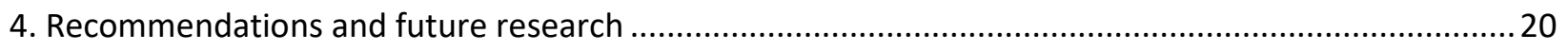

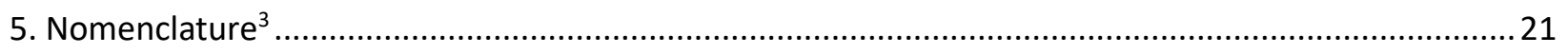

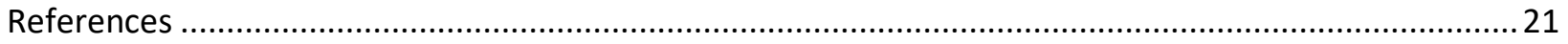

\title{
An evaluation of age effects on driver comprehension of flashing traffic signal indications using multivariate multiple response analysis of variance models
}

\author{
Alex Drakopoulos \\ Department of Civil and Environmental Engineering, Marquette University, Milwaukee, WI \\ Richard W. Lyles \\ Department of Civil and Environmental Engineering, Marquette University, Milwaukee, WI
}

\section{Abstract}

Objective: The objective of this experiment was to identify whether drivers comprehended traffic signals differently when turning left at signalized intersections where traffic signals were in "flashing mode" operation. Method: Multivariate multiple response analysis of variance models were used to analyze the simultaneous effects of displayed color combination, age, and geographical location on signal message interpretation. Data were gathered in a laboratory environment. Results: Left-turn and through-signal color combination had a significant effect on subject comprehension. Comprehension 
was found to be lowest for displays flashing red only, followed by displays flashing red on the left-turn, and yellow on the through-signal, with best comprehended displays flashing yellow only. No overall significant age effects were identified, with one minor exception. No geographical region effects were identified. Signal section arrangement and the use of an arrow or circular illuminated lens had no significant effect on comprehension. Discussion: Traffic signal displays in "flashing mode" operation were previously identified as the least well-comprehended displays for drivers turning left. The present effort identified that this is mainly due to displays flashing red indications on the through-signal. Comprehension of displays flashing yellow indications on the through-signal is comparable to that of permitted left-turn indications. Impact on the Industry: There is a need to develop alternatives for signal displays flashing red indications on the through-signal because a large percentage of drivers facing such indications mistakenly think they have the right-of-way when, in fact, they do not. However, use of such displays on minor streets intersecting major streets cannot currently be avoided when signals are placed in flashing operation. Practitioners using flashing signal operations need not be concerned about signal message comprehension differences among age groups. They can use any among the analyzed alternative signals that convey a given message without impacting signal message comprehension.

\section{Keywords}

Highway safety; Human factors; Traffic control; Traffic safety; Driver comprehension

\section{Abbreviations}

R-R left-turn signal flashing red indication through-signal flashing red indication DK-R left-turn signal not illuminated (dark) through-signal flashing red indication $R-Y$ left-turn signal flashing red indication through-signal flashing yellow indication $Y-Y$ left-turn signal flashing yellow indication through-signal flashing yellow indication DK-Y left-turn signal not illuminated (dark) through-signal flashing yellow indication

\section{Problem statement}

The population of older persons is increasing faster than any other age group in the United States today and concurrently, the percentage of older people who drive is increasing dramatically Comsis Corporation, 1985, Transportation Research Board, 1988. Given the expectations of significantly higher numbers of older drivers in the coming years, it is important to identify and address traffic safety issues related to this age group and take measures to assure that their driving needs are met.

One of the most crucial issues identified so far has been the high concentration of older drivers involved in serious crashes (i.e., injury and fatal) within the signalized intersection environment. A signalized intersection crash pattern emerges, with a shift from crashes involving vehicles moving straight, to those involving vehicles executing a turn, as drivers age. Older driver overinvolvement in serious signalized intersection crashes has been partially attributed to increased frailty with advancing age; also the higher severity associated with turning crashes, particularly head-on and broadside collisions between left-turn and opposing through traffic. It has been noted that older drivers are disproportionately more likely to be cited for failure to yield the right-of-way and illegal turns - particularly in head-on and broadside intersection crashes (McKelvey \& Stamatiadis, 1989). 
Physical and mental condition parameters more likely to deteriorate with age such as ocular (Owsley, 1999) and auditory fitness, increased perception-reaction time, increased decision-making time, a higher tendency toward confusion, inattention, and forgetfulness have been analyzed as possible crash experience explanatory variables Guerrier et al., 1999, Lerner, 1993, Lerner, 1995. Laboratory tests measuring driver mental ability, as well as interactions of mental and physical capabilities, have successfully correlated older subject poor laboratory test scores with poor performance in the field, a promising step toward a better understanding of older driver crash causality Stelmach \& Nahom, 1992, Stutts et al., 1998.

The intersection environment presents one of the greatest challenges for driver mental capacity due to the presence of conflicting vehicular and pedestrian traffic movements, and the need for quick decisionmaking in response to signs, signals, other drivers' actions, and so forth. Turning left at signalized intersections may be the most mentally demanding driving task within the intersection environment, since drivers have to correctly interpret right-of-way priorities depending on left-turn phasing type (e.g., permitted left-turns when a circular green indication is displayed), judge gaps in opposing vehicular and conflicting pedestrian traffic, and perform a turn across a typically unmarked path Guerrier et al., 1999, Hancock, 1990, Hancock \& Caird, 1993, Knoblauch, 1995, Summala, 1996. If indeed increased mental demands placed on the driver significantly contribute in crashes, it is reasonable to expect that a simpler driving environment will lead to a better (lower) crash experience. Simplifications in the left-turning task at signalized intersections can be expected to be beneficial, particularly to older drivers who are overinvolved in serious crashes while performing this maneuver. Left-turn signal indications are rife with complexity, given the variety of left-turn right-of-way rules, and signal displays used to convey these rules. Indeed, the illuminated left-turn signal lens shape may be circular or an arrow; illuminated lenses may be green, yellow, or red; lens illumination may be continuous or flashing; one or two left-turn signal lenses may be illuminated simultaneously (e.g., green arrow and circular red); the left-turn signal appearance may differ - either three vertically stacked sections, or sections in a "doghouse" arrangement (see Fig. 1 rightmost column) may be present, and the meaning of a left-turn signal indication may depend on the through-signal indication (as detailed in Section 3.4). 


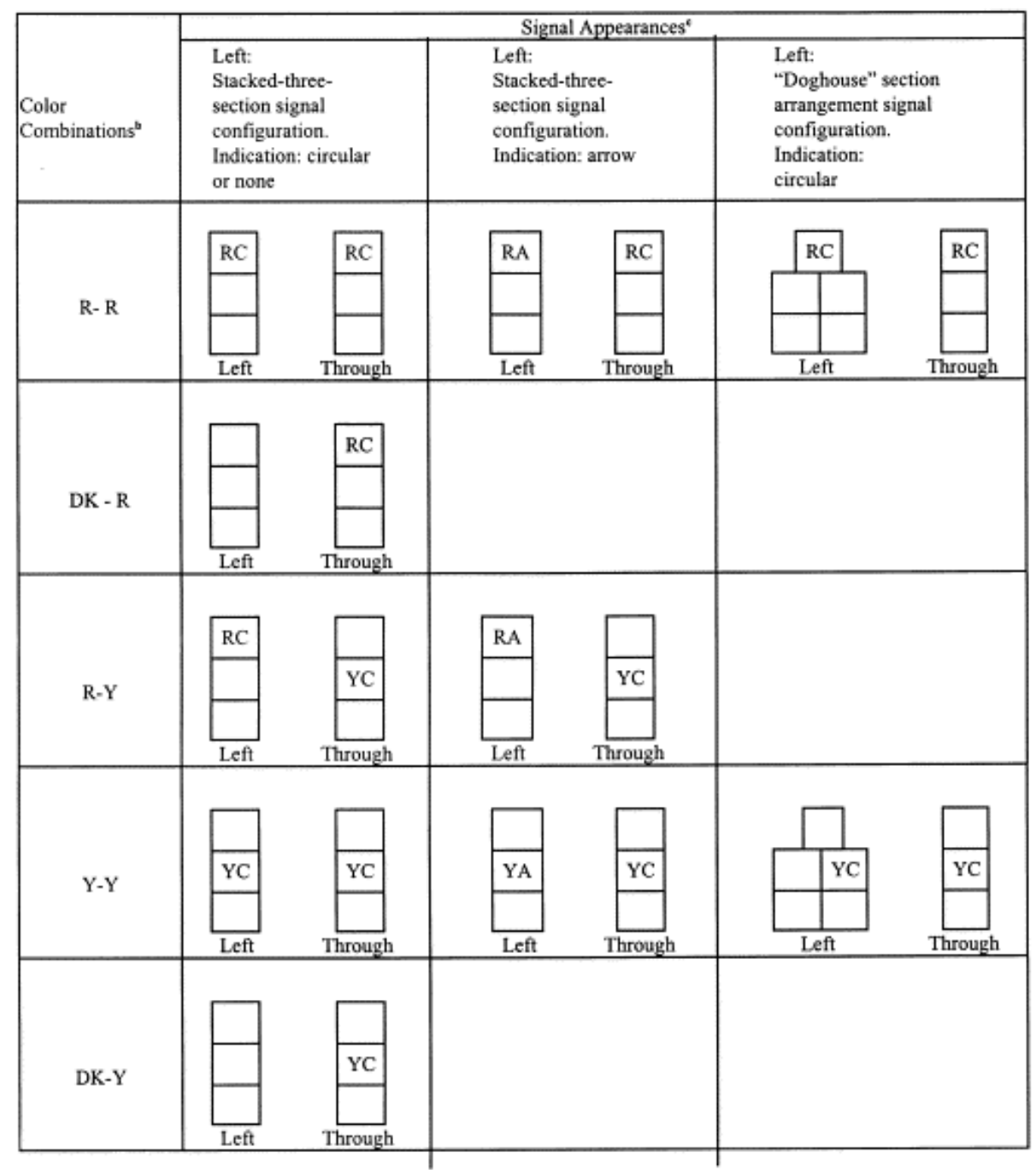

a $\mathrm{R}-$ Red, $\mathrm{Y}-$ Yellow, $\mathrm{A}=$ Arrow, $\mathrm{C}=$ Circular, DK $=$ Dark Signal Face (no illuminated lens).

b Abbreviation Example: $\mathrm{R}-\mathrm{Y}=\mathrm{Red}$ indication on the left-turn and yellow indication on the through signal; see "Abbreviations used in the text" section.

c Left - Left turn signal, Through = Through signal; see Nomenclature part for other definitions.

Fig. 1. Examined flashing operations color combinations and signal configurations. (a) $R=$ red, $Y=y e l l o w, A=a r r o w$, $\mathrm{C}=$ circular, $\mathrm{DK}=$ dark signal face (no illuminated lens). (b) Abbreviation example: $\mathrm{R}-\mathrm{Y}=$ red indication on the left-turn and yellow indication on the through-signal; see abbreviations in the text. (c) Left=left-turn signal, Through=through-signal; see Nomenclature section for other definitions.

The present effort examines driver comprehension of left-turn right-of-way rules when signals are operating in "flashing mode." It is common practice in many areas in the United States to display flashing red and/or yellow signal indications when traffic volumes drop below a given threshold late at night, in order to reduce vehicular delays. ${ }^{1}$ Despite the wide use of flashing mode operation, very few researchers have examined its impacts.

A number of studies have concentrated on driver comprehension of traffic signs and pavement markings Dewar et al., 1994, Hawkins et al., 1993, Knoblauch \& Pietrucha, 1987, Pietrucha, 1989. Although there is no universal agreement among these studies on the statistical significance of the age effect on 
comprehension, a comprehension decline with driver age is apparent for most examined signs and markings. Left-turn signal display comprehension studies have typically focused on normal (not flashing) signal operations and have also identified a comprehension deterioration with advancing age Bonneson \& McCoy, 1994, Curtis et al., 1988, Drakopoulos \& Lyles, 1997, Hummer et al., 1990, Williams et al., 1992. However, the studies measured age effects using different age cohorts, data and/or methodologies, and conclusions on the significance of the relationships between age and comprehension vary as the following brief discussion illustrates. Hummer and Sinha (1990) and Hummer, Montgomery and Sinha (1990) analyzed incorrect answers for permitted and protected leftturn signal displays and identified no significant age effects. Curtis et al. performed an age significance test for each of 83 displays based on correct answers and identified significant age differences for 38 of the displays. The study included many normal and flashing left-turn signal operations.

Drakopoulos and Lyles (1997) performed a comprehension comparison between displays used to convey different left-turn right-of-way messages and identified a significant comprehension deterioration with advancing age; also significant comprehension differences between displays used for the yellow phase (message: "prepare to stop"; serious error rate 1\%), the red phase ("stop"; $3.7 \%$ ), the permitted phase ("complete the turn without stopping if there is no opposing traffic"; 8.3\%), and during flashing operations (messages explained in what follows; $12.6 \%$ ).

The present effort examines driver comprehension performance for the five left-turn and through-signal color combinations used in practice during flashing operations (each row in Fig. 1 represents such a color combination). For the sake of economy, color combinations are abbreviated to R-R, DK-R, R-Y, DK$Y$, and $Y-Y$ in what follows (see Fig. 1). Displays conveying identical messages but differing either in leftturn signal lens type (circular or arrow) or signal appearance (stacked-three-section, or "doghouse" section arrangement), were tested for three of the five color combinations ( $R-R, R-Y$, and $Y-Y$ ). Comparisons among displays conveying identical messages were performed in order to identify and recommend best-comprehended displays. Because data were collected in four jurisdictions and subjects in a given jurisdiction may/may not have been exposed to a particular display, the existence of regional comprehension biases was also investigated.

\section{Method}

\subsection{Data}

A laboratory experiment to measure driver comprehension of various left-turn signal displays was part of a 1988 study funded by the U.S. Federal Highway Administration (Curtis et al., 1988) to investigate traffic signal displays used for left-turn control. The study was contracted to JHK and Associates, which in turn subcontracted Ketron Inc. to conduct the laboratory experiment.

Driver comprehension was evaluated based on the responses of 191 individuals to a set of slides depicting 83 different signal displays used in left-turn phasing, projected on 17 signal backgrounds, similar to the one depicted in Fig. 2. Subjects were recruited through newspaper advertisements in Philadelphia, PA; Seattle, WA; Dallas, TX; and Lansing, MI; and were paid US\$25 to participate in the 2-h experiment. 


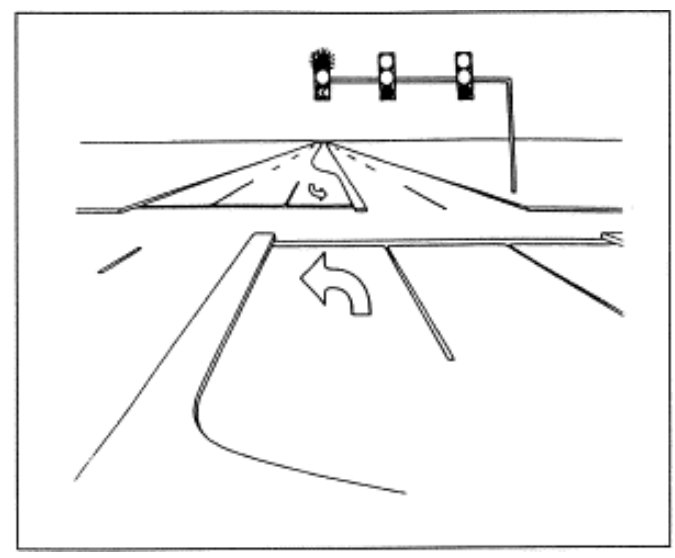

Fig. 2. Typical laboratory display.

\subsection{Experiment protocol}

The experiment protocol involved using a set of slide projectors set up to simulate the color, shape (circular or arrow), and mode of operation (continuously illuminated or flashing) of real signal displays. (A flashing projector was used to project the appropriate flashing indications). The 83 displays were shown to subjects in two prearranged random sequences, not necessarily following the sequence of operation of individual signal displays. Two subject groups with similar sex and age distributions were formed at each testing location and each group was assigned one of the prearranged display sequences at random. This was done to provide some control over order-of-presentation effects, but also to keep the laboratory experiment within the available resource limitations.

After being given a brief introduction about the purpose of the experiment (i.e., driver understanding of signal displays), subjects were shown signal display slides (similar to Fig. 2) and were told to imagine that they were driving in the left-turn lane at the bottom of the screen and wanted to turn left. They were instructed to answer yes or no for each slide (display) to each of the five options for action presented in Table 1.

Table 1. Options for action-laboratory experiment

(a) Turn left, you have the right-of-way (=protected left turn).

(b) Turn left without stopping unless you have to wait for a large enough gap in the opposing traffic (=permitted left turn).

(c) Stop. Then turn left when there is a large enough gap in the opposing traffic.

(d) Stop. Then turn left when there is a large enough gap in the cross street traffic.

(e) Stop. Wait until the signal changes to indicate that you may proceed.

If, for example, the display showed left-turn and through flashing circular yellow indications, the correct answers to options (a) through (e) were respectively N, Y, N, N, N. If the individual's response was $Y, N$, $\mathrm{N}, \mathrm{N}, \mathrm{N}$, then, that response was incorrect. Thus, a subject's answer could be classified either as "correct" or "incorrect" according to whether the response agreed with a set of predetermined correct answers.

Subjects were instructed to ask questions if the color or shape of a lens was not clear, but were not allowed to ask questions pertaining to the meaning of a display. Subjects were also warned that certain 
displays intentionally involved a "dark" signal (i.e., no illuminated lenses on the signal). The experimenter would ask if everybody was done before proceeding to the next slide. It should be noted here that the intent of the study was only to depict a realistic signal appearance, not a realistic driving environment. What was evaluated was whether signal appearance, illuminated lens shape and color, and combination of left-turn and through illuminated lenses intuitively led subjects to correct responses. Allowing adequate time to respond was appropriate, keeping in mind that the experiment did not measure physical (visual) ability or ability to make decisions under time pressure. Before the test initiation, subjects were given a chance to answer five trial questions in order to eliminate learning curve effects.

\subsection{Differences between original and current analysis}

The final report of the original study (Curtis et al., 1988) included an analysis of subject responses based on a dichotomous classification of responses (correct/incorrect). One variable was examined at a time (e.g., use of circular vs. arrow flashing lens) based on comparisons between two displays. Subject age findings were limited to correct answer rate comparisons among four age groups (up to 30 years, 31 to 45,46 to 60 , and older than 60 years of age) for one display at a time.

The dichotomous categorization of subject responses into correct and incorrect, used in the original analysis, did not provide the level of detail necessary for recommending signal displays based on subject comprehension. For example, an error indicating that subjects chose to stop when they had the right-ofway is less serious (a "minor" error) than one indicating they thought they had the right-of-way when they did not (a "serious" error). A minor error can be expected to have mainly delay effects (the driver remains stopped longer than necessary), but a serious error can be expected to lead into a crash with a vehicle moving in the opposite or cross direction. Because minor errors during the typically low-volume nighttime conditions when flashing operations are in effect will have minimal delay impacts, the present analysis concentrates exclusively on serious errors.

The present effort uses a repeated measures general linear model Barcikowski, 1983, SPSS, 1997 in order to analyze the simultaneous effect of study location (regional bias), and subject age on serious errors for multiple displays. The original analysis age groups were used here. Although arbitrarily defined, they offered the advantage of well-balanced age group sizes.

A total of 22 flashing displays were present among the ones presented to the subjects. They were grouped into five categories, based on the combination of left-turn and through-signal colors. Although only serious errors are analyzed here, answers indicating serious errors, minor errors, and correct responses for each of the five display groups are presented in Table 2 for completeness. It should be noted that some jurisdictions do not flash the left-turn signal (the left-turn signal remains dark). The combination of a darkened left-turn signal and flashing red through-signal has the same meaning with displays flashing red on both signals; a darkened left-turn signal and flashing yellow through-signal combination has the same meaning with displays flashing yellow on both signals. 
Table 2. Valid responses for flashing signal operations

\begin{tabular}{|l|l|l|l|}
\hline Color combination- & Subject responses $\underline{\text { a }}$ & & \\
\hline & Serious error & Minor error & Correct \\
\hline R-R and DK-R & a, b, c, d & e & c and d \\
\hline R-Y & a, b, d & c and d & c \\
\hline$Y-Y$ and DK-Y & a & c, d, c and d, e & b \\
\hline
\end{tabular}

$a R=$ red, $Y=y e l l o w, D K=$ dark (no illuminated lens). $R-Y$ : red indication on the left-turn and yellow indication on the through-signal; see abbreviations in the text.

bSee Table 1 for definitions of a, b, c, d, e.

As mentioned above, data were collected at four locations, some of which use flashing indications on the left-turn signal during normal signal operations: Permitted left-turns are indicated by a flashing circular red in Michigan, and a flashing circular yellow in Washington (State). Subject exposure to flashing displays during normal signal operations may affect their comprehension of nighttime/emergency flashing displays, and their answers may vary from those of subjects not exposed to flashing displays during normal signal operations. Thus, an investigation of regional comprehension biases was warranted.

The purpose of the analysis described in Section 2.4 is not only to identify differences between displays (in which case displays offering comprehension benefits would be recommended for use in the field), but also displays that can be used to convey the same message without discernible comprehension differences (in which case, display choice for use in the field will depend on factors other than driver comprehension).

\subsection{Analysis}

After verifying that there was no significant order-of-presentation effect (using analysis of variance to compare error rates between the two sequences of presentation), the analysis proceeded in four stages: Stage 1 examined the simultaneous effects of color combination, subject age, and study location on serious error rates in order to identify which color combinations are best/worst understood and whether findings are universal across age groups and study locations; Stage 2 concentrated on the effects of color combination and location among subjects 60+; Stages 3 and 4 examined whether any of the alternate displays for each of the color combinations $R-R, R-Y$, and $Y-Y$ provided comprehension benefits for all subjects and subjects $60+$, respectively.

In Stage 1, comprehension for all subjects was tested using a multivariate repeated measures general linear model. The preference of a multivariate over a univariate within-subjects model was based on tests for the sphericity assumption, required for univariate models Barcikowski, 1983, Stevens, 1996. Mauchly's Test of Sphericity indicated that none of the tested models satisfied this assumption, therefore only multivariate models (which do not require this assumption) are presented here in the interest of economy in presentation. Separate dependent variables, each measuring the error percentage for one of the five color combinations, were calculated for each subject (variables $-\mathrm{R}-\mathrm{R}$, 
DK-R, R-Y, Y-Y, and DK-Y - see Fig. 1). Thus, the dependent variables were measured based on withinsubjects information. Between-subject factors were subject age (variable "Age") and test location (variable "Location"). Subjects (random effect) were nested within Age (fixed effect) and Location (also fixed effect). Stage 2 analysis was based on a similar model, without the "Age" between-subjects factor. As shown in Fig. 1, multiple displays were tested for three of the five color combinations (R-R, R-Y, and $\mathrm{Y}-\mathrm{Y}$ ). All available displays for a given color combination were used to derive a single error percentage for each individual, because it was desired to analyze the effect of color combination before proceeding in the analysis of differences among displays using the same color combination (which was performed in Stages 3 and 4).

The following null hypotheses Hypothesis 1 , Hypothesis 2 , Hypothesis 3 were examined in turn:

\section{Hypothesis 1}

Mean comprehension scores are equal among all color combinations.

\section{Hypothesis 3}

Mean comprehension scores for age groups do not differ between locations; mean comprehension scores are equal among all age groups; mean comprehension scores are equal between all study locations. $\underline{\text { ? }}$

Interactions were examined first because if they were found to be significant, separate analyses of each level of the between-subjects factors would have been more appropriate than conclusions based on comparisons among levels of between-subjects factors (Barcikowski, 1983).

Stage 2 specifically targeted the older driver group, which displayed significantly lower comprehension of permitted and protected displays in a previous analysis (Drakopoulos \& Lyles, 1997).

Stage 2 aimed to identify best-comprehended color combinations, regardless of the specific signal appearances; the question of which among alternate signal appearances (available for color combinations $\mathrm{R}-\mathrm{R}, \mathrm{R}-\mathrm{Y}$, and $\mathrm{Y}-\mathrm{Y}$ - Fig. 1) were better comprehended among all subjects and older subjects, was addressed in Stages 3 and 4, respectively. Again, the emphasis on older subjects in Stage 4 was motivated by significant comprehension differences between age groups identified in previous work for permitted and protected displays. Because the number of displays within each analyzed category was very small to assume a normal distribution for error rates, a nonparametric statistic (requiring no assumptions about the underlying distributions) was used: Cochran's $Q$ statistic for related samples (Conover, 1999) was appropriate, given the repeated measures experimental design. Because Cochran's test applies to dichotomous variables, subjects' answers had to be converted to dichotomous outcomes. It was most critical to address "serious errors," thus the rest of the answers (i.e., correct or minor error answers) were referred to as "other" for the purposes of this analysis.

Results are presented in the following sections, organized in the four sequential stages presented above. The term "CC" will be used in what follows to refer to the five dependent color combination variables ( $R-R, D K-R, R-Y, D K-Y$, and $Y-Y$ ) collectively in the presentation of multivariate statistics. Case-wise deletion was applied for missing values. 
2.5. Results - Stage 1: all subjects

Comprehension descriptive statistics for Stage 1 are presented in Table 3 .

Table 3. Descriptive statistics - all subjects

\begin{tabular}{|c|c|c|c|c|}
\hline Age group & Mean & Standard deviation & $N$ & \\
\hline \multirow[t]{5}{*}{$\mathrm{R}-\mathrm{R}$} & $16-30$ & 0.252 & 0.338 & 47 \\
\hline & $31-45$ & 0.270 & 0.364 & 48 \\
\hline & $46-60$ & 0.301 & 0.313 & 44 \\
\hline & $61-75$ & 0.379 & 0.360 & 39 \\
\hline & Total & 0.297 & 0.345 & 178 \\
\hline \multirow[t]{5}{*}{ DK-R } & $16-30$ & 0.163 & 0.332 & 47 \\
\hline & $31-45$ & 0.222 & 0.403 & 48 \\
\hline & $46-60$ & 0.356 & 0.396 & 44 \\
\hline & $61-75$ & 0.239 & 0.366 & 39 \\
\hline & Total & 0.243 & 0.379 & 178 \\
\hline \multirow[t]{5}{*}{ R-Y } & $16-30$ & 0.076 & 0.174 & 47 \\
\hline & 31-45 & 0.064 & 0.148 & 48 \\
\hline & $46-60$ & 0.068 & 0.146 & 44 \\
\hline & $61-75$ & 0.120 & 0.201 & 39 \\
\hline & Total & 0.081 & 0.168 & 178 \\
\hline \multirow[t]{5}{*}{ DK-Y } & $16-30$ & 0.007 & 0.049 & 47 \\
\hline & $31-45$ & 0.000 & 0.000 & 48 \\
\hline & $46-60$ & 0.023 & 0.151 & 44 \\
\hline & $61-75$ & 0.026 & 0.160 & 39 \\
\hline & Total & 0.013 & 0.108 & 178 \\
\hline \multirow[t]{2}{*}{ Y-Y } & $16-30$ & 0.004 & 0.029 & 47 \\
\hline & $31-45$ & 0.000 & 0.000 & 48 \\
\hline
\end{tabular}




\begin{tabular}{|l|l|l|l|l|}
\hline & $46-60$ & 0.020 & 0.076 & 44 \\
\hline & $61-75$ & 0.004 & 0.027 & 39 \\
\hline & Total & 0.007 & 0.043 & 178 \\
\hline
\end{tabular}

\subsubsection{Testing Hypothesis 1}

$\mathrm{CC} \times$ Location $\times$ Age and CCXLocation interactions were found to be nonstatistically significant (Table 4). Significant effects were identified for Color Combinations $\times$ Age interactions using Wilks' multivariate test. Hypothesis 1 was rejected, that is, for some color combination(s) comprehension means differed between age groups. Contrasts among the dependent variables were examined (see Table 5 ), in order to identify the source of statistical significance in the multivariate test. Only the "R-R minus DK-R" $\left(\mu_{R-R}-\mu_{D K}\right.$ ${ }_{R}$ ) contrast was found to be statistically significantly different than zero, indicating that differences of mean error rates between these two color combinations were statistically significant for some age groups. Indeed, it is quite obvious from Fig. 3 that the 46-60 age group for DK-R displays had an unusually high error rate; for all other color combinations, comprehension profiles were almost parallel (more accurately: where interactions are present, they were nonsignificant). Given that the detected significant interactions were limited in scope (confined to one color combination and due mainly to one age group), it was decided to proceed with testing $\underline{\text { Hypothesis } 2 .}$

Table 4. Within-subjects effects and their interactions - all subjects ${ }^{\mathrm{a}}$

\begin{tabular}{|l|l|l|l|l|l|}
\hline Effect & Hypothesis & & & & \\
\hline & Value & $\boldsymbol{F}$ & $\boldsymbol{d f}$ & Error $d f$ & Significance \\
\hline CCXLocation×Age & 0.789 & 1.083 & 36 & 598 & .343 \\
\hline CC×Location & 0.912 & 1.246 & 12 & 421 & .249 \\
\hline CCXAge & 0.860 & 2.060 & 12 & 421 & .018 \\
\hline CC & 0.533 & $34.857^{\underline{b}}$ & 4 & 159 & .000 \\
\hline
\end{tabular}

aDesign: Intercept+Location+Age+Location×Age; Within-subjects design: CC.

bExact statistic. 
Table 5. Within-subjects contrasts (differences of means) - all subjects

\begin{tabular}{|c|c|c|c|c|c|c|}
\hline Source & CC & Sum of squares & $d f$ & Mean square & $F$ & Significance \\
\hline \multirow[t]{8}{*}{ CCXAge } & R-R minus DK-R & 0.836 & 3 & 0.279 & 4.902 & .003 \\
\hline & DK-R minus $R-Y$ & 1.069 & 3 & 0.356 & 2.622 & .052 \\
\hline & $\mathrm{R}-\mathrm{Y}$ minus DK-Y & 0.039 & 3 & 0.013 & 0.311 & .818 \\
\hline & DK-Y minus $Y-Y$ & 0.025 & 3 & 0.008 & 0.853 & .467 \\
\hline & R-R minus DK-Y & 0.142 & 3 & 0.047 & 0.360 & .782 \\
\hline & DK-Y minus DK-R & 0.751 & 3 & 0.250 & 1.670 & .176 \\
\hline & $R-Y$ minus $Y-Y$ & 0.111 & 3 & 0.037 & 1.251 & .293 \\
\hline & $R-R$ minus $R-Y$ & 0.107 & 3 & 0.036 & 0.323 & .809 \\
\hline \multirow[t]{8}{*}{$\mathrm{CC}$} & $\mathrm{R}-\mathrm{R}$ minus DK-R & 0.647 & 1 & 0.647 & 11.380 & .001 \\
\hline & DK-R minus $R-Y$ & 4.388 & 1 & 4.388 & 32.297 & .000 \\
\hline & $\mathrm{R}-\mathrm{Y}$ minus DK-Y & 0.798 & 1 & 0.798 & 19.062 & .000 \\
\hline & DK-Y minus $Y-Y$ & 0.016 & 1 & 0.016 & 1.613 & .206 \\
\hline & R-R minus DK-Y & 14.379 & 1 & 14.319 & 109.243 & .000 \\
\hline & DK-Y minus DK-R & 8.927 & 1 & 8.927 & 59.517 & .000 \\
\hline & $R-Y$ minus $Y-Y$ & 1.039 & 1 & 1.039 & 35.065 & .000 \\
\hline & R-R minus $\mathrm{R}-\mathrm{Y}$ & 8.403 & 1 & 8.403 & 75.983 & .000 \\
\hline
\end{tabular}

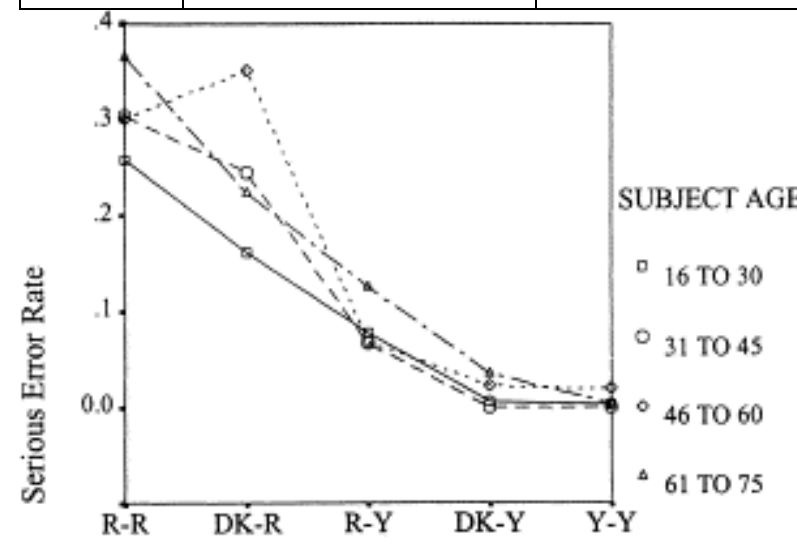

Color Combination 
Fig. 3. All subjects.

\subsubsection{Testing Hypothesis 2}

Significant effects were detected for CC (see Table 4). Fig. 4 indicates that the least well understood (highest error rate) color combination was $\mathrm{R}-\mathrm{R}$ with an average error rate of $30 \%$, followed by DK-R (24\%), R-Y (8\%), DK-Y (1\%), and Y-Y (1\%). As noted in the discussion of Hypothesis 1 above, these findings held true for all age groups examined together, with the notable exception of an unusually high error rate (36\%) among 46-60-year-olds for DK-R displays.

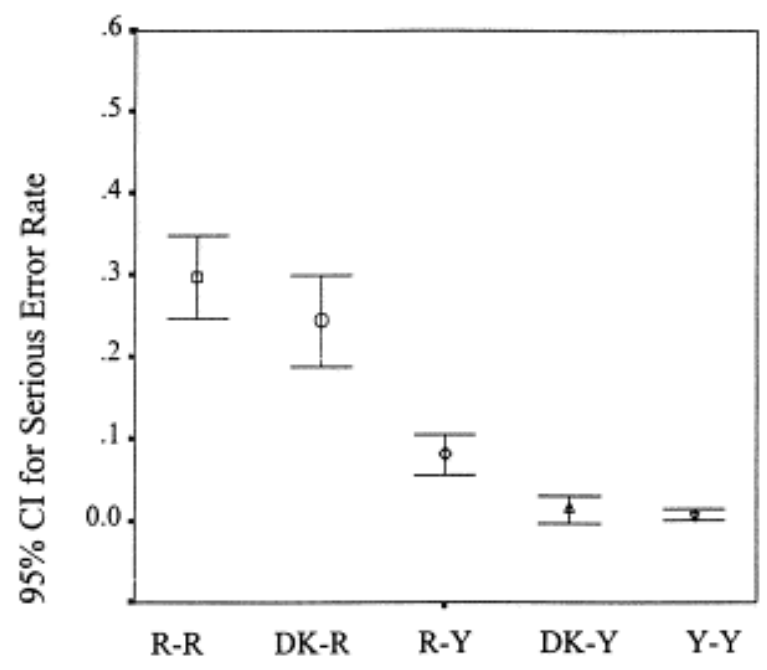

Color Combination

Fig. 4. All subjects.

Contrasts between the dependent variables identified that the DK-Y and $Y-Y$ color combinations were not statistically significantly different among themselves; comprehension differences between all other color combination pairs were statistically significantly different (see Table 5). It should be noted that the only contrasts of practical importance here were those between interchangeable color combinations (color combinations conveying the same right-of-way rules), namely R-R and DK-R; also DK-Y and Y-Y. All other contrasts were between noninterchangeable color combinations and are presented for discussion completeness.

\subsubsection{Testing Hypothesis 3}

Between-subjects factors interaction AgexLocation and main Age and Location effects were not found to be statistically significant (Table 6).

Table 6. Between-subjects effects - all subjects

\begin{tabular}{|l|l|l|l|l|l|}
\hline Source & Sum of squares & $\boldsymbol{d f}$ & Mean square & $\boldsymbol{F}$ & Significance \\
\hline Intercept & 2.967 & 1 & 2.967 & 129.229 & .000 \\
\hline Location×Age & 0.117 & 9 & 0.013 & 0.568 & .822 \\
\hline Location & 0.133 & 3 & 0.044 & 1.938 & .125 \\
\hline
\end{tabular}




\begin{tabular}{|l|l|l|l|l|l|}
\hline Age & 0.077 & 3 & 0.026 & 1.114 & .345 \\
\hline Error & 3.719 & 162 & 0.023 & & \\
\hline
\end{tabular}

Although it is quite evident from Fig. 3 that the comprehension of subjects $60+$ followed the general comprehension trend of different color combinations, the analysis proceeded with Stage 2 for a complete treatment of these subjects, solely motivated by findings in previous work (Drakopoulos \& Lyles, 1997).

\subsection{Results - Stage 2: $60+$ subjects}

Descriptive statistics for subjects $60+$ are presented in Table 7.

Table 7. Descriptive statistics - subjects 60+

\begin{tabular}{|l|l|l|l|}
\hline & Mean & Standard deviation & $\boldsymbol{N}$ \\
\hline R-R & 0.379 & 0.360 & 39 \\
\hline DK-R & 0.239 & 0.366 & 39 \\
\hline R-Y & 0.120 & 0.201 & 39 \\
\hline DK-Y & 0.026 & 0.160 & 39 \\
\hline Y $Y$ & 0.004 & 0.027 & 39 \\
\hline
\end{tabular}

\subsubsection{Testing Hypothesis 1}

Location $\times$ CC interactions were nonstatistically significant (Table 8), as was expected from Stage 1 findings.

Table 8. Within-subjects effects - older drivers ${ }^{\text {a }}$

\begin{tabular}{|l|l|l|l|l|l|}
\hline Effect & Hypothesis & & & & \\
\hline & Value & $\boldsymbol{F}$ & $\boldsymbol{d f}$ & Error $\boldsymbol{d f}$ & Significance \\
\hline CCXLocation & 0.750 & 0.815 & 12 & 85 & .635 \\
\hline CC & 0.413 & $11.349^{\underline{b}}$ & 4 & 32 & .000 \\
\hline
\end{tabular}

aDesign: Intercept+LOCATION Within Subjects Design: CC.

bExact statistic.

\subsubsection{Testing Hypothesis 2}

CC was statistically significant (Table 8), as expected. R-R displays were least well comprehended (error rate $38 \%$ - see Fig. 5 and Table 7). Tests of within-subjects contrasts (differences of means between pairs of color combinations) indicated that differences between R-R displays and all other types of displays were statistically significant; all other adjacent color combinations did not have statistically significant differences; all nonadjacent color combinations (Fig. 5) had significant differences (Table 9). Best-comprehended displays were those used for permitted left-turns, especially the $\mathrm{Y}$-Y color combination (error rate $0.4 \%$ ). Comprehension followed Stage 1 trends, as expected from Fig. 3. 


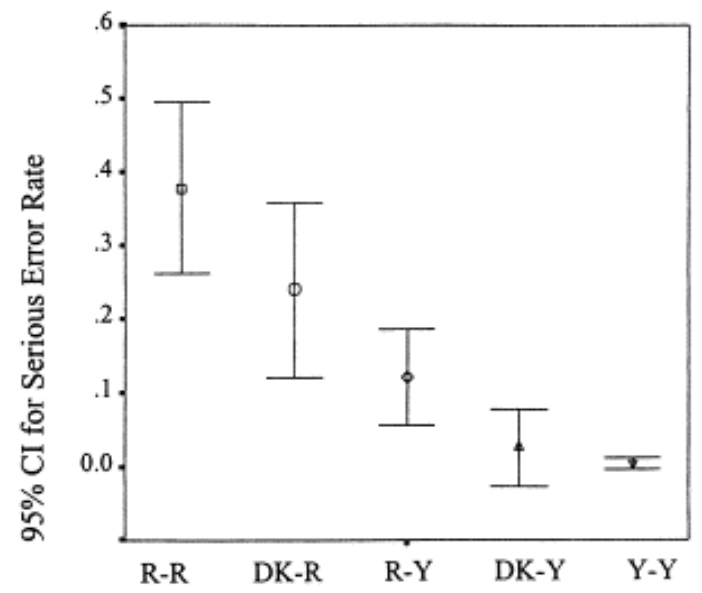

Color Combination

Fig. 5. Subjects $60+$.

Table 9. Within-subjects contrasts (differences of means) - subjects 60+

\begin{tabular}{|l|l|l|l|l|l|l|}
\hline Source & CC & Sum of squares & $\boldsymbol{d} f$ & Mean square & $\boldsymbol{F}$ & Significance \\
\hline CC & R-R minus DK-R & 0.756 & 1 & 0.756 & 13.969 & .001 \\
\hline & DK-R minus R-Y & 0.362 & 1 & 0.362 & 2.277 & .140 \\
\hline & R-Y minus DK-Y & 0.303 & 1 & 0.303 & 3.890 & .057 \\
\hline & DK-Y minus Y-Y & 0.037 & 1 & 0.037 & 1.482 & .232 \\
\hline & R-R minus R-Y & 2.164 & 1 & 2.164 & 14.382 & .001 \\
\hline & DK-R minus DK-Y & 1.328 & 1 & 1.328 & 7.886 & .008 \\
\hline & R-R minus DK-Y & 4.088 & 1 & 4.088 & 23.602 & .000 \\
\hline & DK-R minus Y-Y & 1.811 & 1 & 1.811 & 12.805 & .001 \\
\hline & Y-Y minus R-Y & 0.554 & 1 & 0.554 & 12.704 & .001 \\
\hline & R-R minus Y-Y & 4.907 & 1 & 4.907 & 35.229 & .000 \\
\hline
\end{tabular}

2.6.3. Testing $\underline{\text { Hypothesis } 3}$

Comprehension was found not to differ significantly among study locations for older subjects (Table 10), as expected from Stage 1 results.

Table 10. Between-subjects effects - subjects 60+

\begin{tabular}{|l|l|l|l|l|l|}
\hline Source & Sum of squares & $\boldsymbol{d f}$ & Mean square & $\boldsymbol{F}$ & Significance \\
\hline Intercept & 0.856 & 1 & 0.856 & 37.710 & .000 \\
\hline
\end{tabular}




\begin{tabular}{|l|l|l|l|l|l|}
\hline Location & 0.017 & 3 & 0.006 & 0.248 & .862 \\
\hline Error & 0.794 & 35 & 0.023 & & \\
& & & & & \\
\hline
\end{tabular}

\subsection{Results - Stage 3: all subjects}

No significant comprehension differences were found between the three alternate displays (circular red or red arrow on a stacked-three-section display, and circular red on a doghouse display - Fig. 1) tested for the R-R color combination. Similarly, no comprehension differences were identified for the three alternate displays tested for the $\mathrm{Y}-\mathrm{Y}$ color combination and the two alternate displays tested for the R-Y color combination (see Table 11).

Table 11. Alternate displays - all subjects

\begin{tabular}{|c|c|c|c|}
\hline $\mathbf{Y}-\mathbf{Y}$ & Circular yellow & Yellow arrow & Circular yellow - doghouse \\
\hline Other & $98.8 \%$ & $98.3 \%$ & $100.0 \%$ \\
\hline Serious error & $1.2 \%$ & $1.7 \%$ & $0.0 \%$ \\
\hline$N$ & & $d f$ & Asymp. sig. \\
\hline 163 & 3.500 & 2 & .174 \\
\hline $\mathrm{R}-\mathrm{Y}$ & Circular red & Red arrow & \\
\hline Other & $92.7 \%$ & $89.8 \%$ & \\
\hline Serious error & $7.3 \%$ & $10.2 \%$ & \\
\hline$N$ & Cochran's $Q$ & $d f$ & Asymp. sig. \\
\hline 167 & 1.087 & 1 & .297 \\
\hline$R-R$ & Circular red & Red arrow & Circular red - doghouse \\
\hline Other & $70.1 \%$ & $73.3 \%$ & $67.2 \%$ \\
\hline Serious error & $29.9 \%$ & $26.7 \%$ & $32.8 \%$ \\
\hline$N$ & Cochran's $Q$ & $d f$ & Asymp. sig. \\
\hline 165 & 1.891 & 2 & .389 \\
\hline
\end{tabular}




\subsection{Results - Stage 4: $60+$ subjects}

Findings parallel those for all subjects: No significant differences were identified between alternate displays for any of the R-R, R-Y, or Y-Y color combinations (Table 12).

Table 12. Alternate displays - subjects $60+$

\begin{tabular}{|c|c|c|c|}
\hline Y-Y & Circular yellow & Yellow arrow & Circular yellow - doghouse \\
\hline Other & $100.0 \%$ & $97.3 \%$ & $100.0 \%$ \\
\hline Serious error & $0.0 \%$ & 2.70 & $0.0 \%$ \\
\hline$N$ & Cochran's $Q$ & $d f$ & Asymp. sig. \\
\hline 31 & 2.000 & 2 & .368 \\
\hline $\mathrm{R}-\mathrm{Y}$ & Circular red & Red arrow & \\
\hline Other & $86.8 \%$ & $81.6 \%$ & \\
\hline Serious error & $13.2 \%$ & $18.4 \%$ & \\
\hline$N$ & Cochran's $Q$ & $d f$ & Asymp. sig. \\
\hline 36 & 0.500 & 1 & .480 \\
\hline$R-R$ & Circular red & Red arrow & Circular red - doghouse \\
\hline Other & $55.3 \%$ & $70.0 \%$ & $63.2 \%$ \\
\hline Serious error & $44.7 \%$ & $30.0 \%$ & $36.8 \%$ \\
\hline$N$ & Cochran's $Q$ & $d f$ & Asymp. sig. \\
\hline 35 & 4.000 & 2 & .135 \\
\hline
\end{tabular}

\section{Discussion}

Fig. 4, Fig. 5 (all subjects and subjects 60+) indicate that the previously identified poor overall performance of flashing displays (Drakopoulos \& Lyles, 1997) is mainly due to the R-R and DK-R color combinations with up to $30 \%$ and $38 \%$ serious errors for all and older subjects, respectively. Although these percentages may seem high, they are in line with previous findings of $23 \%$ "gross errors" for permitted left-turns during normal signal operations (Hummer \& Sinha, 1990), especially if one takes into account that flashing operations are expected to have a higher error rate than permitted left-turns during normal signal operations (Drakopoulos \& Lyles, 1997). Comprehension differences among age 
groups were not found to be statistically significant overall; older subjects had a higher error rate for R-R and R-Y displays, but age differences were hardly detectable for DK-R, DK-Y, and especially for $Y-Y$ displays (Table 3). No comprehension differences were detected among study locations. Subject exposure to flashing signal indications during normal signal operations at some study locations apparently did not have a significant impact on their comprehension of nighttime/emergency flashing operations.

\subsection{R-R and DK-R}

Given that R-R and DK-R displays convey the same message and that DK-R displays have significantly lower overall error rates (conclusion from Table 3, Table 5), use of DK-R over R-R displays may be recommended, if better driver comprehension is desired. All drivers, except the 46 to 60 age group, will experience comprehension improvements over R-R displays (Fig. 3). Despite disadvantages specific to this age group (the only age-related detected effect in this analysis), overall comprehension improvements of approximately $6 \%$ less serious errors can be expected (from $30 \%$ to $24 \%$ - Table 3 ).

If $\mathrm{R}-\mathrm{R}$ displays are to be used, the three analyzed left-turn signal displays (circular lens on a stackedthree-section signal display; circular lens on a doghouse display; or arrow lens on a stacked-three display), can be used interchangeably from a message comprehension point of view - no benefits have been identified for any display among all or older subjects Table 11, Table 12. Thus, the choice of signal display will be based on other factors (e.g., driver comprehension of left-turn indications displayed during normal signal operations, uniformity of signal displays within a given jurisdiction in order to simplify the driving environment; technical considerations).

\subsection{R-Y}

Older subjects had a slightly higher error rate (but not statistically significantly different) than other drivers for R-Y displays Table 3 Table 6 . Because no comprehension differences were detected between left-turn signals flashing a circular red or a red arrow for all or the older subjects Table 11, Table 12, the two types of signal displays can be viewed as interchangeable from a comprehension point of view.

\subsection{Y-Y and DK-Y}

Finally, Y-Y displays have no identifiable comprehension benefits over DK-Y displays Table 3 , Table 5 . Differences between all and older subjects are very small for DK-Y and almost nonexistent for $Y-Y$ displays. No comprehension differences were detected among the three alternate $Y-Y$ signal displays examined among all, also among older subjects Table 11, Table 12. Thus, the three signal displays were found to be interchangeable from a comprehension point of view.

\subsection{Connections with previous work}

An explanation for the poor comprehension of certain left-turn signal displays (in terms of the complexity of the mental process required to decipher their messages) was offered previously (Drakopoulos \& Lyles, 1997). The poor comprehension of R-R indications in comparison to Y-Y can be explained similarly. R-R indications require left-turning drivers to consult not only the left-turn signal (red message: stop) but also the through-signal (red message: opposing through - and possibly crossstreet - traffic have priority). A flashing yellow indication on the left-turn signal conveys the (unique) message of a permitted left-turn, and there is no need to consult the through-signal for such displays. Thus, in the case of flashing operations, more mentally demanding displays $(R-R)$ are associated with 
poorer comprehension performance than less demanding displays ( $Y-Y)$, as was the case for normal operations displays. Results here make apparent that the poor flashing signal comprehension identified earlier is mainly due to R-R and DK-R indications ( $30 \%$ and $24 \%$ serious error rates, respectively). However, $\mathrm{R}-\mathrm{Y}$ indication comprehension ( $8 \%$ serious error rate) is comparable to that of permitted indications (8\%), and that of $Y-Y$ displays (1\%) is identical with the yellow interval comprehension (1\%) - the best-comprehended among all types of displays examined in the earlier work.

The goal of the present analysis is to ultimately help reduce crashes at signalized intersections, especially those crashes involving older drivers. A few points, however, should be kept in mind before comprehension-based recommendations lead to the use of specific color combinations during flashing operations in the field:

- Studies have documented that, despite increased vulnerability at night, older drivers are not overinvolved in nighttime crashes, Ball et al., 1998, Evans, 1991 presumably because they are effective in self-regulating their crash exposure. Thus, perhaps the 46-60 age group should be the main focus when analyzing flashing display comprehension. The high error rate identified in this group for DK-R displays may then reverse the overall preference for DK-R over R-R displays;

- Serious error rate percentages analyzed here will not translate directly into crash percentages (a $1 \%$ reduction in serious errors will not lead to a $1 \%$ reduction in the number of crashes), since the measured driver comprehension errors are only one of many synergistic underlying crash causes. Furthermore, accurate evaluation of field mental workload is a complex issue (Waard \& Brookhuis, 1997), and identification of its comprehension component presents a major challenge; and,

- Driver comprehension of all indications displayed during normal and flashing operations should be evaluated before comprehension-related safety benefits can be expected from the use of a specific signal display used to convey a given set of messages. Comprehension benefits during flashing operations, for example, may more than be offset by comprehension disadvantages during the normal operations permitted phase, which will be in use during a significant part of the 24-h period while the intersection is experiencing much higher traffic volumes.

Given the absence of significant age and study location effects (with the only exception of the poor performance of the 46-60 age group for DK-R displays), no specific age group or drivers within a specific geographic area will be put at a comprehension disadvantage where a better-comprehended color combination is used during flashing operations, or where any of the equally well-comprehended signal displays are used.

\section{Recommendations and future research}

The following recommendations can be made based on the findings summarized in Section 3 :

- A recommendation of DK-R or R-R displays will depend on whether a significant number of 60+ drivers is present or not: when present, a DK-R would be recommended, when not, a R-R may be recommended in order to benefit the 46-60 age group.

- $\quad$ DK-Y and Y-Y displays can be used interchangeably.

- Any of the examined alternate signal displays within each of the R-R, R-Y, and $Y-Y$ color combinations (see Fig. 1) can be used without a comprehension disadvantage. 
The high error rate for R-R displays points to a need to develop and evaluate alternate signal displays to convey their intended message. These displays have the highest error rates among displays used in normal as well as in flashing operations.

Because yellow through lenses are used on higher priority streets, and (lower priority) cross-streets must use red through lenses, red through indications will be present at every intersection using flashing signals (i.e., it is not possible to use better-comprehended yellow through indications on both streets). Thus, practitioners cannot avoid problems related to the use of red indications wherever they decide to use flashing signal operations.

It is assumed that poorer signal indication comprehension will lead to more crashes within the signalized intersection environment, however, the signal comprehension-safety relationship needs to be quantified, since the end goal in analyzing driver comprehension is to reduce the number of crashes at signalized intersections.

\section{Nomenclature ${ }^{3}$}

\begin{tabular}{|l|l|}
\hline $\begin{array}{l}\text { Normal (full color) } \\
\text { signal operation }\end{array}$ & $\begin{array}{l}\text { Signal operation under high-volume normal traffic conditions (vs. flashing } \\
\text { signal operation during nighttime/low volume/emergency traffic conditions). }\end{array}$ \\
\hline Signal indication & $\begin{array}{l}\text { The illumination of a traffic signal lens or a combination of several lenses at } \\
\text { the same time. }\end{array}$ \\
\hline Signal section & An optical unit and housing assembly, capable of displaying one indication. \\
\hline Signal face & $\begin{array}{l}\text { That part of a highway traffic signal (a combination of signal sections) which } \\
\text { controls one or more traffic movements in a single direction. }\end{array}$ \\
\hline
\end{tabular}

\section{References}

Ball et al., 1998 K Ball, C Owsley, B Stalvey, D.L Roenker, M.E Sloane, M Graves Driving avoidance and functional impairment in older drivers Accident Analysis and Prevention, 30 (3) (1998), pp. 313 322

Barcikowski, 1983 R.S Barcikowski Computer packages and research design: with annotations of input and output from the BMDP, SAS, SPSS, and SPSSX statistical packages, University Press of America, Lanham, MD (1983)

Bonneson \& McCoy, 1994 J.A Bonneson, P.T McCoy Driver understanding of protected and permitted left-turn signal displays Transportation Research Record, 1464 (1994), pp. 42-50

Comsis Corporation, 1985 Comsis 1983-1984 Nationwide personal transportation study: summary of travel trends, U.S. Department of Transportation, Washington, DC (1985)

Conover, 1999 W.J Conover Practical nonparametric statistics (3rd ed.), Wiley, New York (1999) Curtis et al., 1988 O.P Curtis, K.S Opiela, D.L Guell Signal displays for left-turn control, final report, United States Federal Highway Administration, Office of Highway Safety, McLean, VA (1988)

Dewar et al., 1994 R.E Dewar, D.W Kline, H.A Swanson Age differences in comprehension of traffic sign symbols Transportation Research Record, 1456 (1994), pp. 1-10

Drakopoulos \& Lyles, 1997 A Drakopoulos, R.W Lyles Driver age as a factor in comprehension of leftturn signals Transportation Research Record, 1573 (1997), pp. 76-85

Evans, $1991 \mathrm{~L}$ Evans Older-driver risks to themselves and to other road users Transportation Research Record, 1325 (1991), pp. 34-41 
Federal Highway Administration, 1988 Federal Highway Administration Manual on uniform traffic control devices for streets and highways (1988 ed.), U.S. Department of Transportation Federal Highway Administration, Washington, DC (1988)

Giblin, 1989 J.M Giblin Traffic signal installation and maintenance manual, Institute of Transportation Engineers, Prentice-Hall, Englewood Cliffs, NJ (1989)

Guerrier et al., 1999 J.H Guerrier, P Manivannan, S.N Nair The role of working memory, field dependence, visual search, and reaction time in the left turn performance of older female drivers Applied Ergonomics, 30 (2) (1999), pp. 109-119

Hancock, 1990 P.A Hancock Driver workload during differing driving maneuvers Accident Analysis and Prevention, 22 (3) (1990), pp. 281-290

Hancock \& Caird, 1993 P.A Hancock, C.K Caird Factors affecting older drivers' left turn decisions, Human Factors Research Laboratory, Center for Transportation Studies University of Minnesota, University of Minnesota, Minneapolis (1993)

Hawkins et al., 1993 H.G Hawkins, K.N Womack, J.M Mounce Driver comprehension of regulatory signs, warning signs, and pavement markings Transportation Research Record, 1403 (1993), pp. 67-82

Hummer et al., 1990 J.E Hummer, R.E Montgomery, K.C Sinha Motorist understanding of and preferences for left-turn signals Transportation Research Record, 1281 (1990), pp. 136-147

Hummer \& Sinha, 1990 J.E Hummer, K.C Sinha Motorist understanding of and preferences for left turn signals, University of North Carolina at Charlotte Transportation Academy, Charlotte, NC (1990)

Knoblauch, 1995 R Knoblauch Traffic operations control for older drivers, United States Federal Highway Administration, Office of Safety and Traffic Operations Research and Development, TurnerFairbank Highway Research Center, McLean, VA (1995) v, p. 96

Knoblauch \& Pietrucha, 1987 R.L Knoblauch, M.T Pietrucha Motorists' comprehension of regulatory, warning, and symbol signs, United States Federal Highway Administration, Washington, DC (1987)

Lerner, 1993 N.D Lerner Brake perception-reaction times of older and younger drivers Proceedings of the Human Factors and Ergonomics Society Annual Meeting (1993), pp. 206-210

Lerner, 1995 N.D Lerner Older driver perception-reaction time for intersection sight distance and object detection, Federal Highway Administration, McLean, VA (1995) xiii, p. 103

McKelvey \& Stamatiadis, 1989 F.X McKelvey, N Stamatiadis Highway accident patterns in Michigan related to older drivers Transportation Research Record, 1210 (1989), pp. 53-57

Owsley, 1999 C Owsley Vision impairment and driving Survey of Ophthalmology, 43 (6) (1999), pp. 535550

Pietrucha, 1989 M.T Pietrucha Motorist compliance with standard traffic control devices, U.S.

Department of Transportation, Federal Highway Administration, Research Development and

Technology, McLean, VA (1989)

SPSS, 1997 SPSS SPSS advanced statistics 7.5, SPSS, Inc, Chicago, IL (1997)

Stelmach \& Nahom, 1992 G.E Stelmach, A Nahom Cognitive-motor abilities of the elderly driver Human Factors, 34 (1) (1992), pp. 53-65

Stevens, $1996 \mathrm{~J}$ Stevens Applied multivariate statistics for the social sciences (3rd ed.), Lawrence Erlbaum Associates, Mahwah, NJ (1996)

Stutts et al., 1998 J.C Stutts, P.R Stewart, C Martell Cognitive test performance and crash risk in an older driver population Accident Analysis and Prevention, 30 (3) (1998), pp. 337-346 
Summala, 1996 H Summala Bicycle accidents and drivers' visual search at left and right turns Accident Analysis and Prevention, 28 (2) (1996), pp. 147-153

Transportation Research Board, 1988 Transportation Research Board Transportation in an aging society: improving mobility and safety for older persons, National Research Council, Transportation Research Board, Committee for the Study on Improving Mobility and Safety for Older Persons, Washington, DC (1988)

Waard \& Brookhuis, 1997 D.D Waard, K.A Brookhuis On the measurement of driver mental workload Traffic and Transport Psychology: Theory and Application (1997), pp. 161-171

Williams et al., 1992 J.C Williams, S.A Ardekani, S.A Asante Motorist understanding of left-turn signal indications and auxiliary signs Transportation Research Record, 1376 (1992), pp. 57-63 